\title{
EVALUATING A RESTRUCTURED UNIVERSITY PORTAL FRAMEWORK WITH REUSABLE COMPONENTS
}

\author{
Rami Raba ${ }^{1}$, Mohammed Awad ${ }^{2}$, Marawan Al-Jemeli ${ }^{3}$ \\ ${ }^{1}$ Information System Department, Limkokwing University Cyberjaya, Malaysia \\ ramiraba@yahoo.com \\ ${ }^{2}$ Faculty of Applied Engineering and Urban Planning University of Palestine Alzhra, Gaza, Palestine \\ m.awad@up.edu.ps \\ ${ }^{3}$ Information System Department, Limkokwing University Cyberjaya, Malaysia \\ marwan.aljemeli@limkokwing.edu.my
}

\begin{abstract}
The loose coupling relation between components of a students' portal at a university is an essential concept to reduce the dependency between these components on each others, and to increase the reusability of these components. This loose coupling feature can be achieved by applying the distribution and interoperability between the components of the students' portal. A recent research has redefined the students' portal framework and included distribution between the framework components to support the reusability of these components, while no researches have been done to evaluate this framework that has distributed interoperable components. This paper evaluates involving distribution and interoperability in the students' portal framework using case study approach. The evaluation results have proved efficiency of components' distribution and interoperability of the students' portal framework.
\end{abstract}

Keywords: University Portal, Student Portal, Portal Framework, Reusable Components.

\section{INTRODUCTION}

As a summary to what has been explored in paper [1], figure 1 explores the new framework in which all academic and administrative departments of a university portal are distributed to components of a complete portal. These components are software packages or modules that encapsulate a set of related data. As shown in figure 1, the users that are connected to the internet/intranet can view and update their profiles and specific needs via registration and admission, students' affairs, financial affairs, graduate studies, library and/or other extended components. Moreover, there is an Orchestration Point that is considered as a station to verify the validity of user and to identify his/her request. The new students' portal framework that is restructured based on Service Oriented Architecture (SOA) [1]. A prototype is developed and tested for the purpose of realizing the framework.

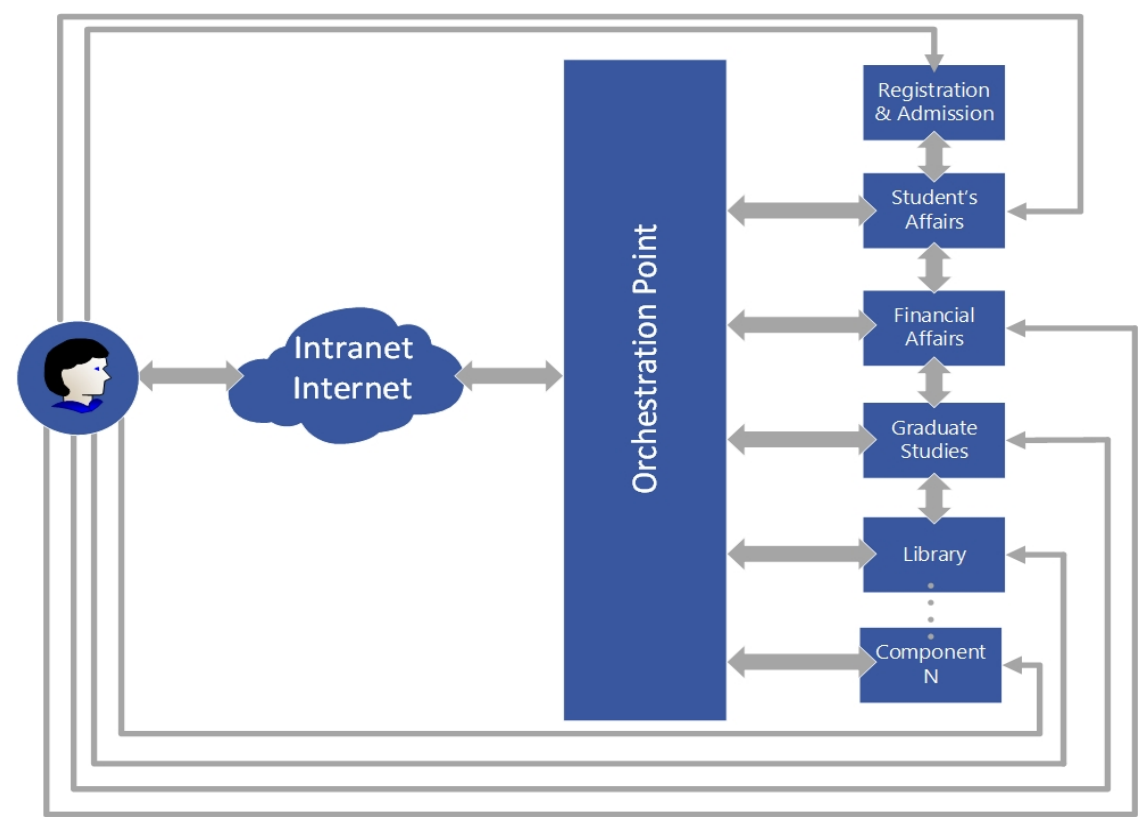

Figure 1. The students' portal framework based on SOA 


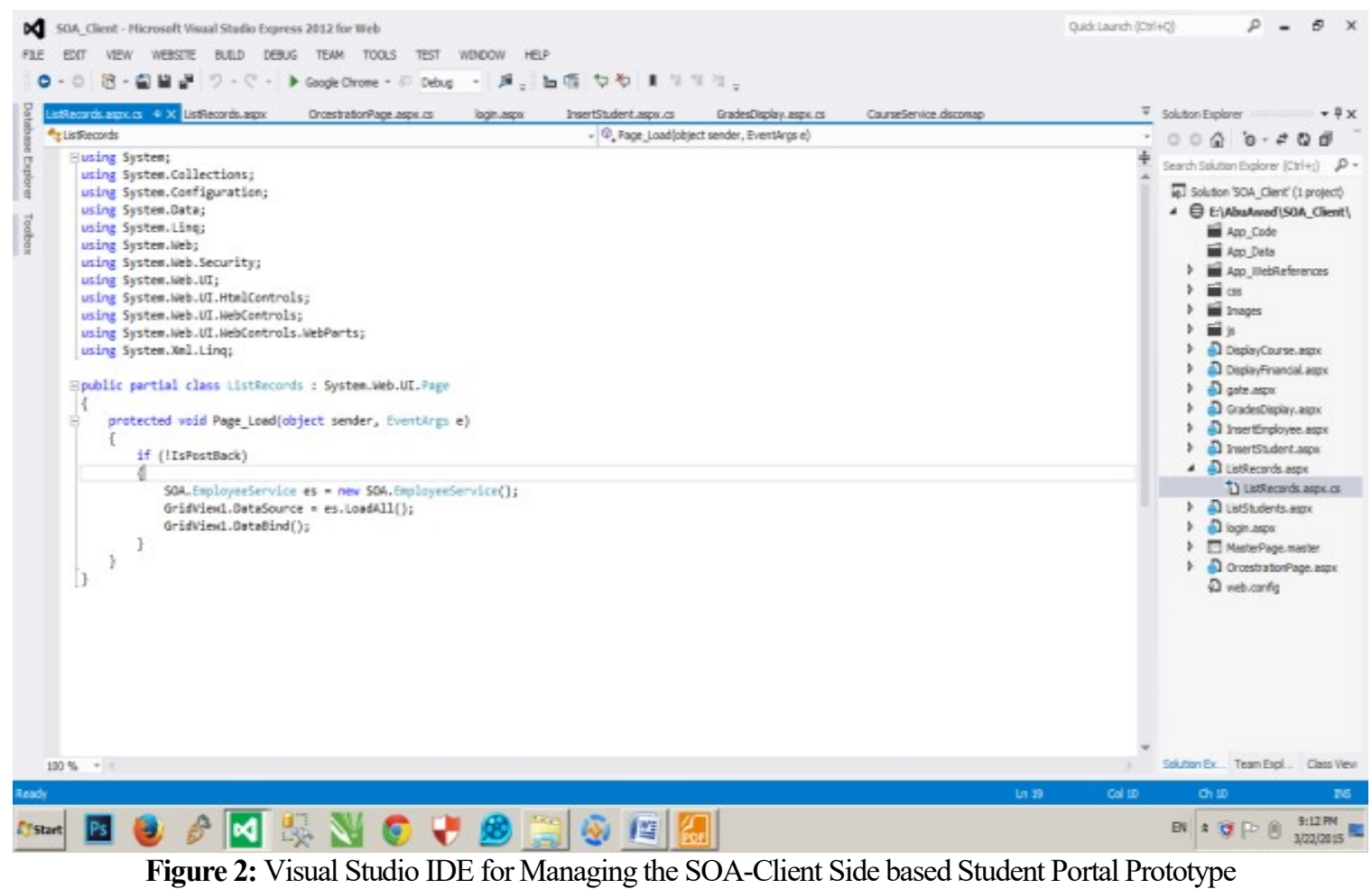

This paper explores the case study that is conducted for evaluating the framework of figure 1. Al-Azhar UniversityGaza [2] is selected to conduct the case study based on its data.

For the deployment of the Students' Portal components, Visual Studio IDE is used for this purpose and for the purpose of managing the web/application servers. In addition, the Visual Studio IDE is used for managing the database connections. A screenshot for this IDE is represented by figure 2 .

As shown in Figure 1, the Students' Portal Gate component is deployed in a separate visual studio IDE based distributed application. In addition, figure 3 shows the server side and the orchestration point deployed in a separate web service. This decomposition of deploying the prototype components is done for the purpose of applying the distribution concept among the prototype components.

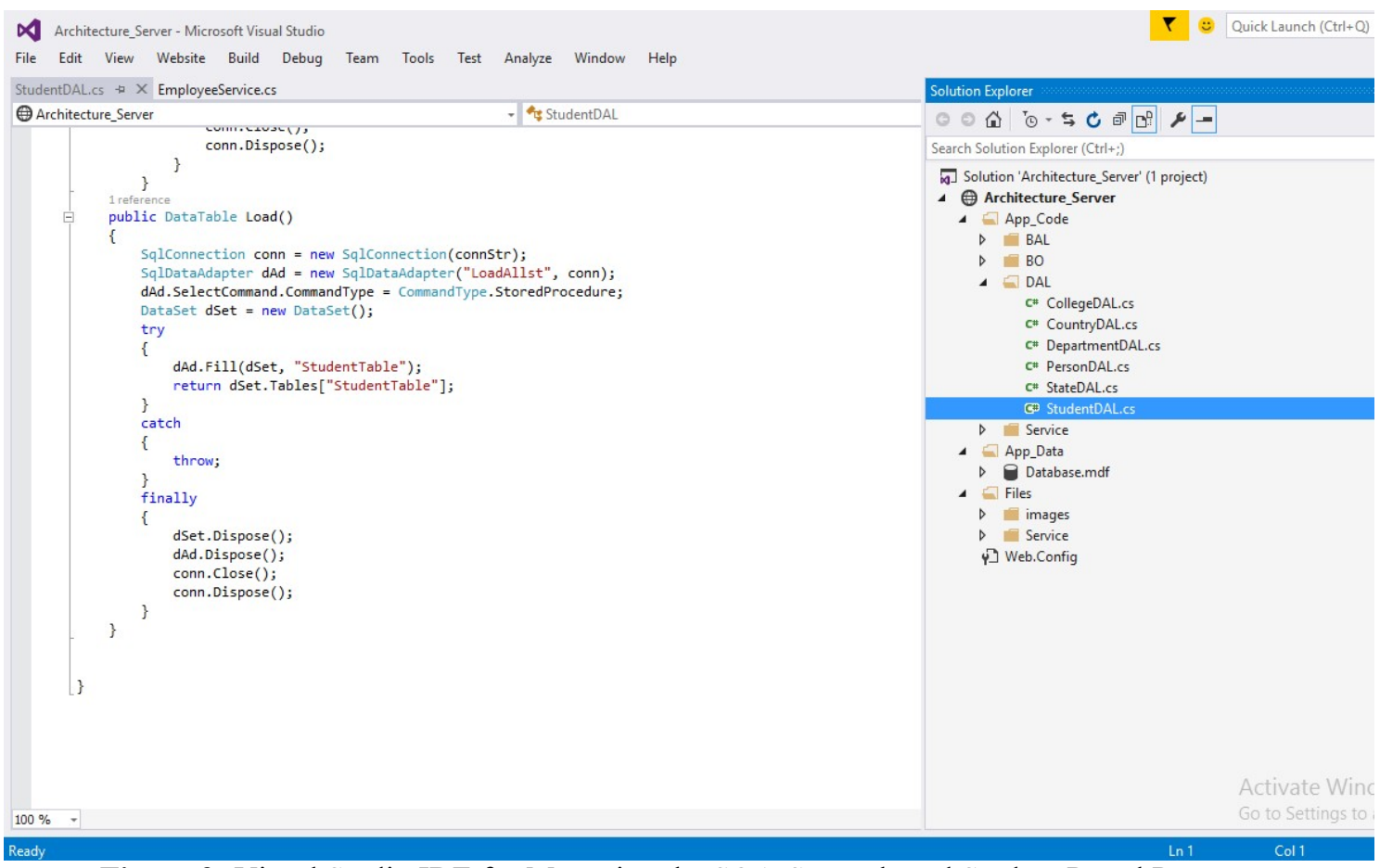

Figure 3: Visual Studio IDE for Managing the SOA-Server based Student Portal Prototype 
On the other hand, and for the purpose of comparison, in traditional Students' Portal tools, the student interacts and sometimes inserts students' data directly to the data source, as shown in figure 4 without passing through an orchestration service [3-6].

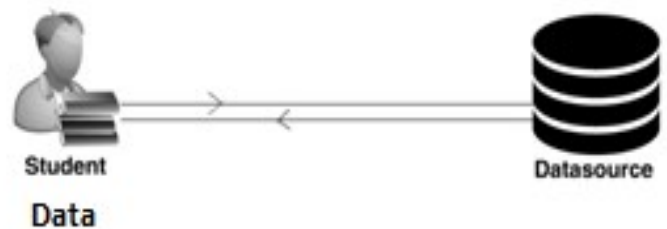

Figure 4:Students' Portal Traditional Process

\section{DESIGN AND METHODS OF APPLYING} THE CASE STUDY

The method used to conduct the case study has adopted the recommendation of [7] that include four stages: (1) design the case study, (2) conduct the case study, (3) case study evidence, and (4) case study conclusion. These four recommended steps are followed in conducting each of the case study phases. A common design for the case study is explored in figure 5, while the details of conducting the case study are listed below.

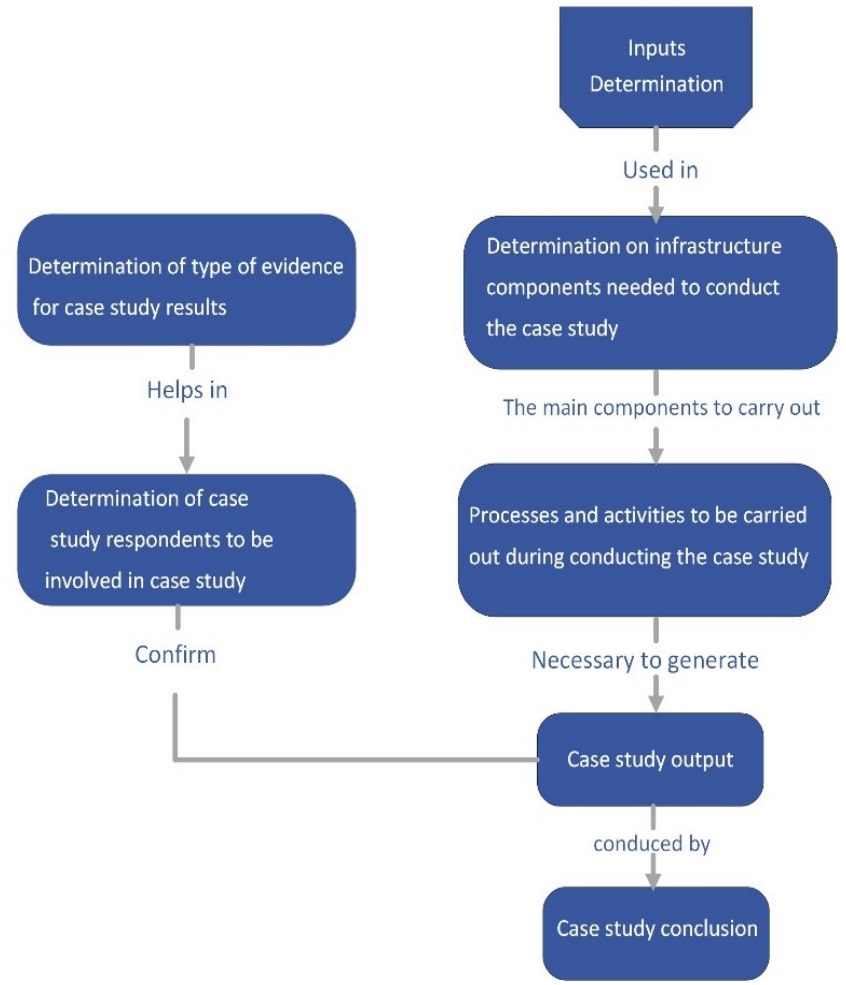

Figure 5: Case Study Design

Table I. Details of the Case Studies based on Case Study Design of Figure 5

\begin{tabular}{|c|c|}
\hline Inputs determined & $\begin{array}{l}\text { A database schema related to the source databases. This schema included auto generated } \\
\text { text data for the purpose of conducting the case study. The auto generated data has } \\
\text { matched the original data in data type and format to represent the original data that is } \\
\text { private to Al-Azhar University-Gaza. }\end{array}$ \\
\hline $\begin{array}{l}\text { Determined infrastructure } \\
\text { components needed to conduct the } \\
\text { case study }\end{array}$ & $\begin{array}{l}\text { Using the traditional students' portal tool } \\
\text { Using the traditional students' portal simulated the current situation at Al-Azhar } \\
\text { University-Gaza where the database is created and managed by Microsoft SQL Server } \\
\text { DBMS that includes its own Portal which is SQL Server Integration Services. In Al- } \\
\text { Azhar University-Gaza computational system. } \\
\text { Using SOA-based students' portal prototype } \\
\text { The SOA-based students' portal prototype is deployed over four different servers, two of } \\
\text { them with Redhat Linux operating systems and the other two with Windows } 2003 \text { server } \\
\text { operating systems. Apache Tomcat Jakarta Web servers as runtime environments are } \\
\text { installed over the servers with Redhat Linux operating systems, Students' Portal } \\
\text { administrator (Client) component is deployed separately on the same application server } \\
\text { where the Orchestration point deployed on. Thereafter, the execution of the Students' } \\
\text { Portal functionalities is done using browsers of normal client PCs. }\end{array}$ \\
\hline $\begin{array}{l}\text { Processes and activities to be carried } \\
\text { out during conducting the case study }\end{array}$ & $\begin{array}{l}\text { 1. Preparing infrastructure components needed to conduct the case study such as } \\
\text { data sources connections and software installations. } \\
\text { 2. Inserting required fields using the traditional Students' Portal tool. } \\
\text { 3. Selecting required fields using traditional using students' portal tool. } \\
\text { 4. Inserting required fields using SOA-based Students' Portal Prototype. } \\
\text { 5. Selecting required fields using SOA-based Student Portal Prototype. }\end{array}$ \\
\hline $\begin{array}{l}\text { Determined type of evidence for case } \\
\text { study results }\end{array}$ & $\begin{array}{l}\text { Direct observation is chosen because this type of evidence covers events in real time, } \\
\text { covers event context. }\end{array}$ \\
\hline $\begin{array}{l}\text { Determined case study respondents } \\
\text { to be involved in the case study }\end{array}$ & Four IT Professional at Al-Azhar university-Gaza. \\
\hline Case study output & Successfully loaded data to the final Students' Gate . \\
\hline
\end{tabular}




\section{CASE STUDY: APPLYING STUDENTS' PORTAL FUNCTIONALITIES ON AL- AZHAR UNIVERSITY- GAZA USING TRADITIONAL AND NEW STUDENTS' PORTAL TOOLS}

Al-azhar University-Gaza is an Educational Association and independent non-profit organization that has twelve faculties, which are Faculty of Arts, Faculty of Education, Faculty of Information \& Communication Technology, Faculty of Medicine, Faculty of Pharmacy, Faculty of Sharia, Faculty of Media, Faculty of Intermediate Studies, Faculty of Law, Faculty of Economics, Faculty of Medical Professions, and Faculty of management \&Finance.

\section{A. Students' Business Needs}

Al-azhar University-Gaza does many statistical reports for the purpose of the decision making such as students' performance reports, staff performance reports, and financial reports. Doing these types of statistical reports requires skipping the difficulties to extend the reuse of students' portal components and being compatible with any platform in heterogeneous environments. These types of data fields, which are taken from the Al-Azhar UniversityGaza main database, are remotely managed through the web portal to centralize the management by orchestration point of all components from the different locations for the purpose of generating statistical reports.

\section{B. Required Fields for Al-azhar University-Gaza database}

This case study had applied the Students' Portal functionalities on sample partial source DB schema of Alazhar University-Gaza shown in Figure 6. The Students' Portal functionalities are applied to the sample Al-azhar table schema and to its auto generated data using both the traditional Students' Portal tool that is used by Al-azhar University-Gaza (MSSQL Server Integration Services) and the SOA-based students' portal prototype.

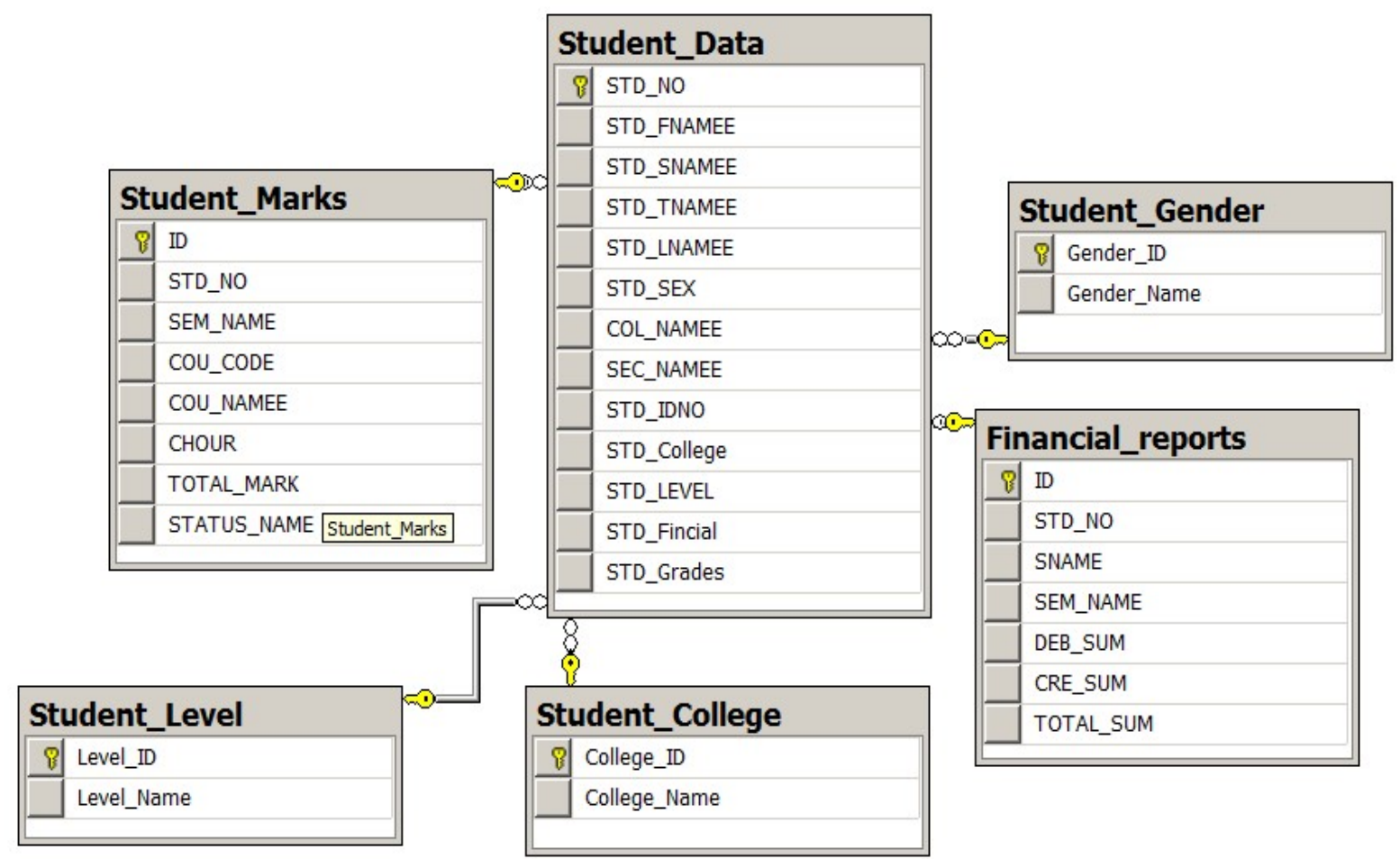

Figure 6 : Partial DB Schema of Al-Azhar University-Gaza

\section{Applying Students' Portal Functionalities Using the Traditional Students' Portal}

Using the traditional students' portal simulated the current situation at Al-azhar University-Gaza where the database is created and managed by Microsoft SQL Server DBMS that includes its own Portal, which is SQL Server Integration Services. In the Al-Azhar University-Gaza computational system.

In this case study Sql Server is used to select the fields needed for the creation of the business process that enables the generation of a reports about the students data in the Arabic subject for February-June, 2013semester. Although, the generation of the report is outside the scope of the Students' Portal functionalities.

\section{SOA-based Prototype}

After using the traditional students' portal tool, this section describes SOA-based students' portal prototype. The SOAbased students' portal prototype is deployed over four different servers, two of them with Redhat Linux operating systems and the other two with Windows 2003 server operating systems. Apache Tomcat Jakarta Web servers as 
runtime environments are installed over the servers with Redhat Linux operating systems, and Students' Portal administrator (Client) component is deployed separately on the same application server where the Orchestration point is deployed. Thereafter, the execution of the Students' Portal functionalities is done using browsers of normal client PCs. Therefore, SOA-based Students' Portal prototype is used here to extract the fields needed for the creation of the business process that enables the generation of a statistical reports about the students performance in the Java II course for February-June, 2011 semester.

\section{GOALS ACHIEVED}

Based on the new students' portal specifications, there are three goals that should be achieved. All goals are the main features of loosely-coupled framework with independent components and relates the usage of the distribution, interoperability, reusability, and extensibility. All goals are listed in this section, and the results of the possibility of achieving each goal using both traditional students' portal component tool and the new students' portal components framework of this case study are listed. The results of achieving both goals were obtained through observation.

\section{a. Goal 1: Achieving Distribution and Interoperability} among students' portal components.

By comparing the usage of the traditional students' portal tool versus the SOA-based students' portal prototype, it is observed that goal \#1 is achieved in using SOA-based students' portal prototype, while using the traditional students' portal tool does not achieve most of the goal parts. The tool of the traditional students' portal is a tightlycoupled tool and its components cannot be distributed. Furthermore, the whole tool is installed on one server because of the impossibility of distributing its components. Therefore, components' Distribution and Interoperability among students' portal components could not be achieved when the traditional students' portal tool is used.

On the other hand, by following the SOA-base students' portal prototype, each component of the SOA-based students' portal prototype is distributed in an orchestrated way that can easily implemented in an University system. Therefore, Components' Distribution and Interoperability is achieved among the students' portal.

\section{b. Goal 2 : Achieving Reusability among students' portal} components.

The new students' portal framework components SOA-based prototype are reusable, which any portal component can be reused because dependent components are already included. Therefore, Components Reusability is achieved among the students' portal.

\section{c. Goal 3: Achieving Extensibility among students' portal} components.
By using the traditional students' portal tool any change or extension on the framework components usually forces a ripple effect of changes to other components because of lack of distribution. Therefore, Components' Extensibility among students' portal could not be achieved when the traditional students' portal tool is used.

On the other hand, the new students' portal framework components SOA-based prototype are easily extensible, which shows that any portal component of a University system can be extended or modified without any effect on other components. Therefore, Components' Extensibility is achieved among the students' portal components. Table 2 shows a checklist that summarizes the observation results of conducting this case study.

Table 2. Observation Results Checklist

\begin{tabular}{|l|c|c|}
\cline { 2 - 3 } \multicolumn{1}{c|}{} & $\begin{array}{c}\text { Using Traditional } \\
\text { Students' Portal } \\
\text { tool }\end{array}$ & $\begin{array}{c}\text { Using SOA-based } \\
\text { Students' Portal } \\
\text { Prototype }\end{array}$ \\
\hline Distributed achieved & NO & YES \\
\hline Interoperability achieved & NO & YES \\
\hline & & \\
Reusability achieved & NO & YES \\
\hline & & \\
Extensibility achieved & NO & YES \\
\hline
\end{tabular}

\section{CONCLUSION AND FUTURE WORK}

The paper has evaluated the SOA-based students' portal prototype by conducting a case study for the purpose of evaluating the prototype of this paper that evaluates the theoretical framework. The case study is conducted with Alazhar University-Gaza that use the students' portal tools. The observed results of conducting the case study has proved the distribution, interoperability, reusability, and extensibility among the new students' portal framework components.

This work has focused on how a conceptual framework for students' portals including the feature of component distribution be defined to enhance the current tightlycoupled portals, while it has not handled the other features of this portal, specifically, the academic features that any academic portal should have, and how these features are affected by an SOA architecture of the portal. Therefore, this could be a future research work that completes the optimum usage of an SOA based students portal.

\section{REFERENCES}

[1] Rami A.Y Raba , M.M.I.A., Students' portal architecture based on SOA. IEEE, 2015(Control, Engineering \& Information Technology (CEIT), 2015 3rd International Conference): p. 1 - 4.

[2] http://www.alazhar.edu.ps/.

[3] Gleason, B.W., Web Portals and Higher Education Technologies to Make IT Persona. A Publication of EDUCAUSE and NACUBO, 2002: p. 87-108. 
[4] Heinz Kredel, H.G.u.K., Ingo Ott, Performance analysis and performance modeling of web-applications. IEEE, 2011: p. 115-122.

[5] Chaoying Ma, L.B., Miltos Petridis and Gill Windall, Towards the Design of a Portal Framework for Web Services Integration. IEEE, 2006.

[6] Kyu-Nyun Kim, J.-G.K., Sung-Jin Kim, Jong-Soo Yang,Choong Young Jung, Dae-Hwa Park, U-WIN : THE UNIVERSITY OF ULSAN WEB BASED INFORMATION NETWORK. Proceedings ofrhe 7th Korea-Russia International Symposium, KORUS 2003, 2003.

[7] Yin, R., Case study research: Design and methods (2nd ed.). 1994(Thousand Oaks, CA: Sage Publishing.). 